\title{
Analysis of the 2012-2016 drought in the northeast Brazil and its impacts on the Sobradinho water reservoir
}

\section{Samara Calçado de Azevedo, Guilherme Pina Cardim, Fernanda Puga, Ramesh P Singh \& Erivaldo Antonio da Silva}

To cite this article: Samara Calçado de Azevedo, Guilherme Pina Cardim, Fernanda Puga, Ramesh P Singh \& Erivaldo Antonio da Silva (2018) Analysis of the 2012-2016 drought in the northeast Brazil and its impacts on the Sobradinho water reservoir, Remote Sensing Letters, 9:5, 438-446, DOI: $10.1080 / 2150704 X .2018 .1437290$

To link to this article: https://doi.org/10.1080/2150704X.2018.1437290

曲 Published online: 06 Feb 2018.

Submit your article to this journal $₫$

Џ Article views: 176

Q View related articles $๘$

View Crossmark data $\nearrow$ 


\title{
Analysis of the 2012-2016 drought in the northeast Brazil and its impacts on the Sobradinho water reservoir
}

\author{
Samara Calçado de Azevedo (iD) ${ }^{a, c}$, Guilherme Pina Cardim (iD) ${ }^{a}$ Fernanda Pugab, \\ Ramesh P Singh ${ }^{c}$ and Erivaldo Antonio da Silva (D) ${ }^{a}$ \\ a'Department of Cartography, São Paulo State University (UNESP), Presidente Prudente, SP, Brazil; \\ ${ }^{b}$ Department of Transportation Engineering and Geodesy, Federal University of Bahia (UFBA), Salvador, \\ BA, Brazil; 'School of Life and Environmental Sciences, Schmid College of Science and Technology, \\ Chapman University, Orange, CA, USA
}

\begin{abstract}
The northeast region of Brazil (NEB) suffers with the worst drought during 2012-2016 that has greatly affected water availability in general, in particular the hydropower reservoirs. We have analyzed a large dataset of satellite measurements and images to understand the variability of precipitation, land surface temperature (LST) and their association with the Normalized Difference Vegetation Index (NDVI), indicator of water and vegetation stress. The drought conditions during 2012-2016 show association of poor rainfall in the year 2012 , an increase of LST $7^{\circ} \mathrm{C}$ above the average, reduction in NDVI upto $30 \%$ and a sharp decrease upto $28 \%$ in Relative Humidity (RH). The largest reservoir of the NEB, Sobradinho, shows decline in surface water upto about $50 \%$ which is clearly evident from the Normalized Difference Water Index (NDWI) for the period 2015-2016 compared to the year 2011.
\end{abstract}

\section{ARTICLE HISTORY}

Received 25 August 2017

Accepted 27 January 2018

\section{Introduction}

Drought events are common in the northeast region of Brazil (NEB) where more than $50 \%$ of drought records in Brazil are concentrated. The predominant semi-arid climate present in the region is characterized by irregular precipitation with the scarcity of rainfall during certain period of the year. Besides the natural land ecosystems and climate dynamics in NEB region, global climate phenomenon related to the El Niño Southern Oscillation (ENSO) has also strongly influenced by frequency and intensity to the dry weather. In addition, due to anomalously displacing the Intertropical Convergence Zone (ITCZ) over the Atlantic sector leads to anomalous rainfall patterns with concentration mainly in the coastal region (Awange, Mpelasoka, and Goncalves 2016; Marengo, Torres, and Alves 2016). Consequently, over last two decades, a history of constant drought was observed in the region with an indication of increased severity much likely by climate change (Barbosa et al. 2006; Cunha et al. 2015; Barbosa and Kumar 2016).

The recent intensive drought developed in the NEB region for the period 2010-2015 (with some relief in between) and extended in the year 2016 has been one of the worsts in the last

CONTACT Samara Calçado de Azevedo samara_calcado@hotmail.com E Department of Cartography, São Paulo State University (UNESP), 305 Roberto Simonsen, Presidente Prudente, SP, 19060-900, Brazil 
decades, compounded by the strong 2015-2016 El Niño, which brought warmer weather and Sea Surface Temperature (SST) (Marengo, Torres, and Alves 2016; Kogan and Guo 2017). In 2015, about 1192 Brazilian's municipalities were hit by drought conditions, mainly located in the semiarid region of NEB (ANA 2016). Such extreme condition is also exacerbated due to anthropogenic activities like deforestation, increased fire frequency and overexploitation of groundwater affecting almost 10 million (Marengo, Torres, and Alves 2016).

One of the greatest hydroelectric power plants of NEB, the Sobradinho hydroelectric dam, have reached upto about 1.98\% lowest level of its capacity in November 2015, which was a historical record, operated close to dead volume. Again in 2016, the reservoir was low (reached $6.76 \%$ of capacity), higher compared with the 2015 year, but it was enough to allow the National Water Agency (ANA) for reduction of reservoir flow, which also happened in the year 2015. Despite of the reduction of flow has maintained the power generation in the region, it has impacted water supplies for multiple uses (Agência Brasil 2015).

The current scenario in the NEB, with likely intensification of extreme droughts and problems with water resources, is a crucial question for overcoming population's resilience to the expected impacts of droughts. The use of remote sensing images and measures to assess the spatio-temporal linkages between meteorological and hydrologic droughts still needed in order to quantify drought severity in terms of reduction in reservoir level. Since Sobradinho represent almost $60 \%$ of the water resource in the NEB region, we have carried out a detailed analysis of meteorological parameters to understand climate variability and to study the possible causes of droughts in NEB region.

\section{Methodology}

\subsection{Study area}

The study area cover the Sobradinho Reservoir (40.8 $-42.5^{\circ} \mathrm{W}, 9.1^{\circ}-10.5^{\circ} \mathrm{S}$ ) located in the north of Bahia state, Brazil (Figure 1). Sobradinho reservoir lies in the semi-arid area of the NE region, characterized by warm summer and mild winter with long lasting droughts periods, plays an important role in the climate variability (Da Silva 2004). The semi-arid climatic

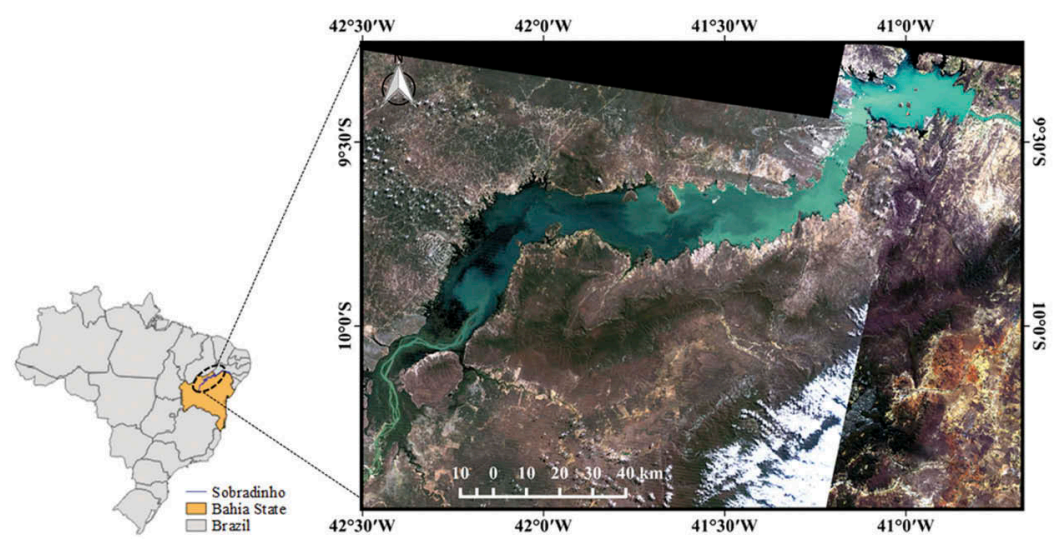

Figure 1. Location of sobradinho reservoir in the North part of Bahia State located in the Northeast of Brazil. Mosaic (RGB321) from Lansat5/TM image (path 217/218 and row 067) of Jun 2011 considering the Sobradinho extension. 
conditions also reflect in the vegetation cover with the presence of grassland, croplands and also shrublands known as caatinga. The Caatinga is a heterogeneous biome responsible by $35 \%$ of cover Brazilian territory and roughly $60 \%$ of NEB, consisting of low shrubs often fragmented and seasonally dry forest (Barbosa et al. 2006; Beuchle et al. 2015).

In terms of power generation, Sobradinho dam stands out as the fourth among a dozen power plants placed at São Francisco River Basin (SFRB). On the other hand, the reservoir is also used to control and regulate water resources in the region, which provides water supply for irrigation. In addition, it has provided an economic growth, which has increased pressure on its natural and water resources due to intense economic activities and agriculture (Cunha et al. 2015; Sun et al. 2016). Furthermore, the surface area of the reservoir is being reduced due to frequent drought periods.

\subsection{Methods and dataset description}

Climatic and hydrologic investigations over a bounding area (latitude $40.0^{\circ}-43.0^{\circ} \mathrm{S}$ and longitude $9.5^{\circ}-12.5^{\circ} \mathrm{W}$ ) that encompass Sobradinho reservoir, are carried out using satellite data obtained through NASA Giovanni portal (http://disc.sci.gsfc.nasa.gov/giovanni/). Land surface temperature (LST) and relative humidity $(\mathrm{RH})$ data from Atmospheric Infrared Sounder (AIRS) instrument onboard of Moderate Resolution Imaging Spectrometer (MODIS) satellite Aqua (AIRX3STM v006 data) with $1^{\circ} \times 1^{\circ}$ of spatial resolution is used and retrieved for the period Jan 2003-Sep 2016. Monthly precipitation rate from Tropical Rainfall Measuring Mission (TRMM) data (3B43 product) and Evapotranspiration (ET) data derived from Global Land Data Assimilation System (GLDAS) are used to characterize seasonal reservoir level variation. GLDAS product is generated through temporal averaging of the 3 -hourly products with $0.25^{\circ}$ of spatial resolution and integrate satellite-based measurements and ground observations which are commonly used for climatic and hydrologic investigations (Rodell et al. 2015).

Although Normalized Difference Vegetation Index (NDVI) from semi-arid areas is low compared with other regions of Brazil, it is strongly dependent on plant water availability in wet months and can be used as an indicator of stressed vegetation from drought events (Cunha et al. 2015). Therefore, we have also analysed vegetative drought from the 16-days MODIS NDVI time series product (MOD13C2 v5) with $5600 \mathrm{~m}$ of spatial resolution.

For the temporal assessment of flooded area of Sobradinho Reservoir, we have constructed mosaics from L1T (Standard Terrain Correction) images of Landsat-5/TM and Landsat-8/OLI considering the Sobradinho extension (path 217/218 and row 067). Based on seasonal droughts that usually occur during winter (Jun-Sep) and spring (Sep-Dec), we have considered months of June and October for the evaluation of water reservoir surface area during the years 2011, 2015 and 2016. The Landsat5 TM images were acquired on June 10/17, 2011, while the Landsat-8 OLI images were acquired on June 12/21 and September 29/2 October 2015; June 07/30 and October 04/29. Multitemporal Landsat images are freely available from the United States Geological Survey (USGS) through the portal https://earth explorer.usgs.gov/. The water body is delineated using Normalized Difference Water Index (NDWI), based on reflectance in green (G) and near infrared (NIR) wavelengths, details about NDWI are given by McFeeters (1996). Both sensors hold similar spectral range at G and NIR bands, which show variations in absorption of energy by water and help in the extraction of water features. A post-process step to remove mixed pixels around the reservoir that are not 
considered as its flooding area is applied using morphological operator area opening that removes objects with an area smaller compared to a given threshold (Soille 2003).

\section{Results and discussion}

\subsection{Methods and dataset description}

Dry scenario in SFRB started as of 2011 based on the seasonal rainfall observation. During the period of 17 years (2000-2016) the Northeast region received less than $900 \mathrm{~mm}$ year $^{-1}$ within the semi-arid zone which includes Sobradinho reservoir. Figure 2 shows the rainfall deviation from the average rainfall for 17 years period 2000-2016. The year of 2012 stands out with the largest negative deviation in precipitation $\left(-265.55 \mathrm{~mm}\right.$ year $^{-1}$ ) compared to the average value of $614.25 \mathrm{~mm}$ year $^{-1}$ for the SFRB. Deficit in precipitation, especially in the years 2012 shows critical situation with below average precipitation rate. In addition, variations due to the seasonal effects such as ENSO signal and Atlantic anomalies are also linked to the warming of the northern part of the tropical Atlantic and somewhat dry rainfall season in the NEB (Lucena, Servain, and Gomes Filho 2011; Cavalcanti 2015).

The severity of dry years from 2012 to 2016 in the NEB was also observed from the MODIS data for the period 2003-2016 (Figure 3). In 2012, LST (Figure 3(a)) has reached $42.5^{\circ} \mathrm{C}$ on March which was the highest temperature for this month within the period assessed, about $7^{\circ} \mathrm{C}$ above the average for this period without considering 2012. Temperatures far above average was registered during the rainy season (Feb-May), extended to dry months (SepOct) in 2012, and followed by 2015-2016 period (with some relief in between) indicating the long-last drought. Decrease in $\mathrm{RH}$ much lower than the 14-year average was also observed (Figure 3(b)). During March 2012 and Oct 2015, RH decreased upto 28\% and almost 12\%, respectively, compared with 14-years average.

\subsection{NDVI drought indicators}

The signs of drought were also monitored from the deficit in vegetation greenness reflected from NDVI values for the period 2003-2016 (Figure 4(a)). Native vegetation is

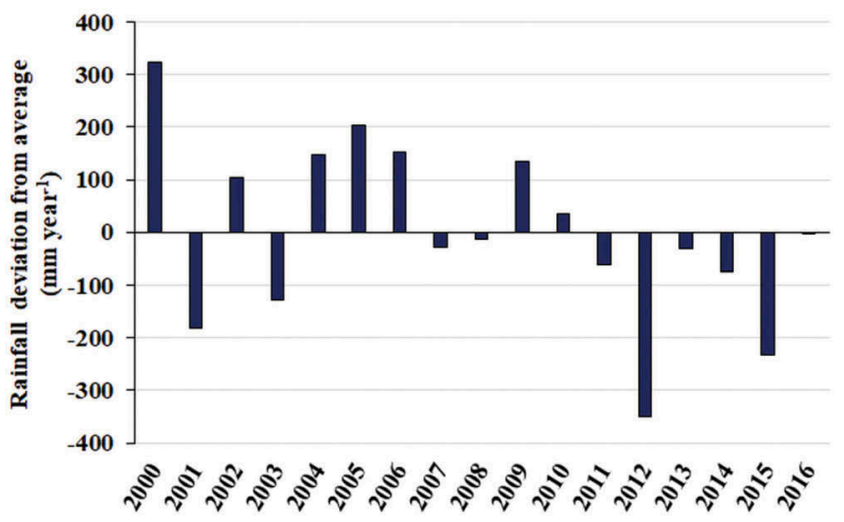

Figure 2. Rainfall deviation $\left(\mathrm{mm}\right.$ year ${ }^{-1}$ ) from 17 years average (2000-2016) in the Northeast Brazil which includes Sobradinho reservoir. 


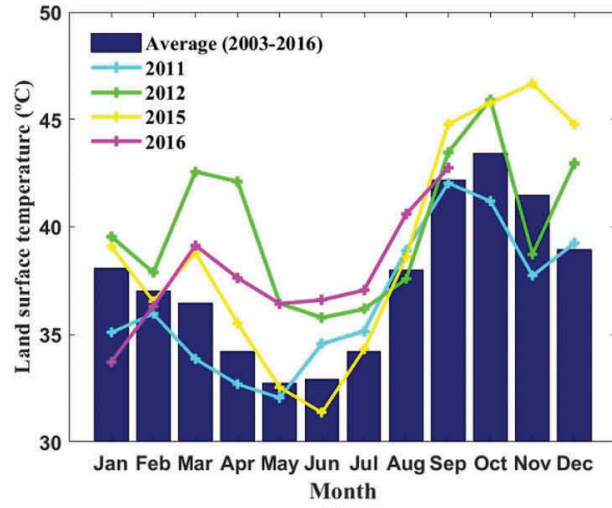

(a)

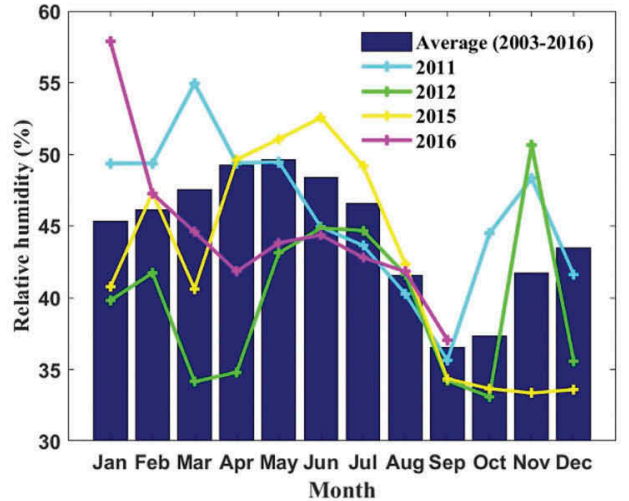

(b)

Figure 3. Monthly comparison of 14-years average (2003-2016) in blue bars and recent dry years (2011, 2012, 2015 and 2016) over Sobradinho area in the Northeast Brazil for the climatological variables: (a) LST and (b) RH.

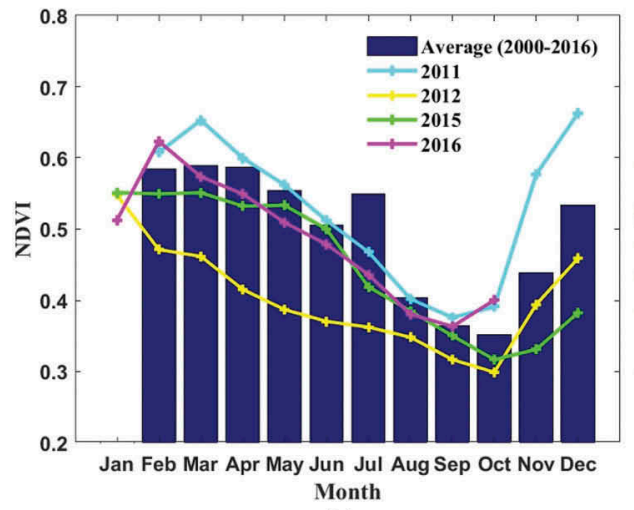

(a)

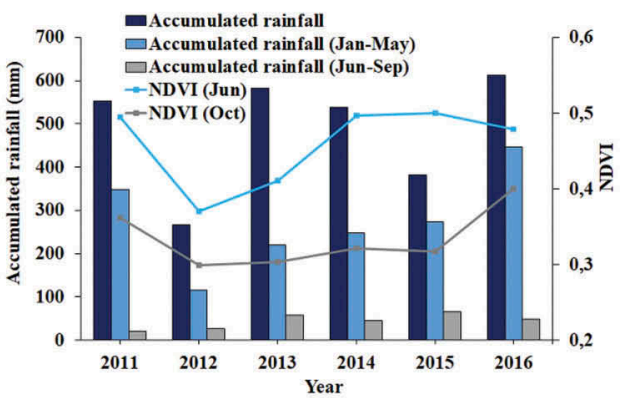

(b)

Figure 4. (a) Yearly average NDVI during the period 2000-2016 (in bars) compared to vegetation stress years (cyan-2011, yellow-2012, green-2015 and purple-2016). (b) Rainfall cumulative (mm/month) considering the whole year (dark blue, in bars), rainy season (Jan-May, light blue) and dry season (Jun-Sep, gray) and relation with NDVI values for Jun (Light blue line) and Oct (Gray line) over Sobradinho area in Northeast Brazil.

composed of shrubs and small trees reaching higher NDVI values $(0.55-0.65)$ during the rainy season. However, in the year 2012, anomalous NDVI values (lower than the average values for the 17-years period 2000-2016) was observed, with $20 \%$ of reduction to all rainy period and reaching upto $30 \%$ in the month of May, that indicates the vegetation stress condition. During the period 2015-2016, NDVI values remained lower than the average values affected by the ENSO that have influenced global weather and earth surface temperature. This condition agrees with Kogan and Guo (2017) that have shown vegetation stressed during El Niño with high correlation for Brazil-north. Moreover, during 2015 the mean NDVI reduction was approximately 10\% and the NDVI further decreased upto $25 \%$ by November and $28 \%$ by December. 
The analysis of rainfall distribution can also be exploited as an indicator for temporal NDVI responses. Figure 4(b) shows the NDVI behavior for the month of June and October with respect to the rainfall during rainy season (Jan-May) and dry season (Jun-Sep). As discussed earlier, 2012 was the driest year with the lowest NDVI value 0.29 as observed in the months of Jun and Oct. Inspite of an increase in rainfall during 2015 compared to 2014, a reduction in NDVI was observed in the month of Oct 2015 and Jun 2016 showing highly stress vegetation. These results confirm that rainfall variability and NDVI association have no direct relation, and events such as ENSO and ITCZ can influence drought events and temperature over the North Atlantic Ocean (Marengo, Torres, and Alves 2016). Moreover, NDVI reduction could also attribute to an increase in LST (highest) in the dry period of 2015 (Figure 3(a)) showing severity of 2015-2016 drought conditions.

The evaporation can also contribute to show evidence and the impacts of drought on agricultural and hydrological systems. Figure 5 shows the comparison between the ET (GLDAS) and LST (AIRS) during the period 2003-2016. The most critical period with lowest ET values was in the year 2012 with a peak in the dry season (especially Sep-Oct) with higher LST and lower RH (see Figure 3(b)). Therefore, the evaporative power increases with an increase in LST with the highest values in the month of 2003 (March) and 2016 (Feb). The increase of ET in the year 2016 was about $60 \%$ in the whole period average (2003-2016). This strong increase in ET in the year 2016 can be attributed to the increasing trend of LST which has been observed since 2012 due to long-lasting strong drought conditions and others influences.

\subsection{Surface water assessment}

The long-lasting drought event faced by the NEB severely affected ground water resources, especially Sobradinho reservoir. We have considered Landsat data during June (after rainy period) and October (dry period). Using NDWI, the surface area is found to decrease in Sobradinho reservoir upto about $42 \%$ in 2015 and $30 \%$ in the

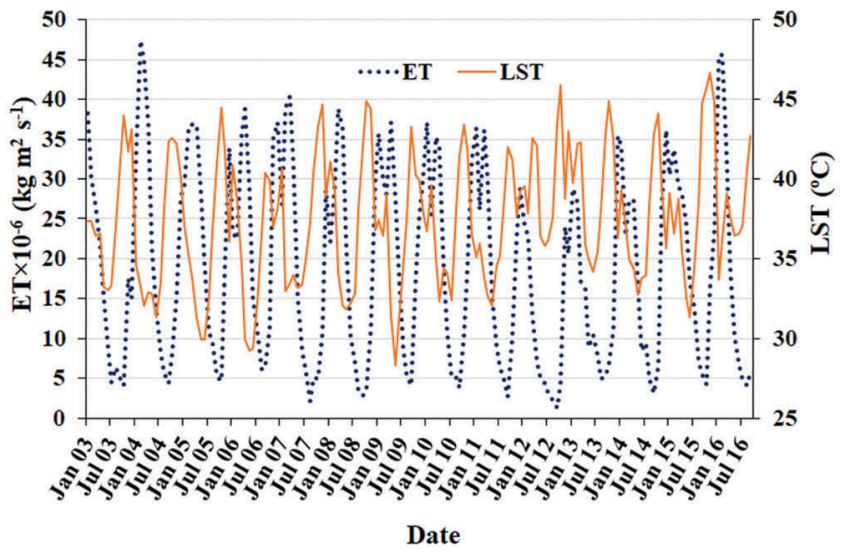

Figure 5. Monthly GLSDA Evapotranspiration (ET) time series (dark blue dotted) expressed in $\mathrm{kg} \mathrm{m}^{-2} \mathrm{~s}^{-1}$ and AIRS LST data $\left({ }^{\circ} \mathrm{C}\right)$ for the period 2003-2016. 
Table 1. Flooded area for Sobradinho reservoir as detected by the spectral water index NDWI in 2011, 2015 and 2016 considering the months of June (after rainy period) and October (dry period).

\begin{tabular}{lcc}
\hline & \multicolumn{3}{c}{ Flooded area $\left(\mathrm{km}^{2}\right)$} \\
\cline { 2 - 3 } Year & June & October \\
\hline 2011 & 2989.5615 & N/A \\
2015 & 1740.6972 & 1484.4046 \\
2016 & 2067.4350 & 1609.6347 \\
\hline
\end{tabular}
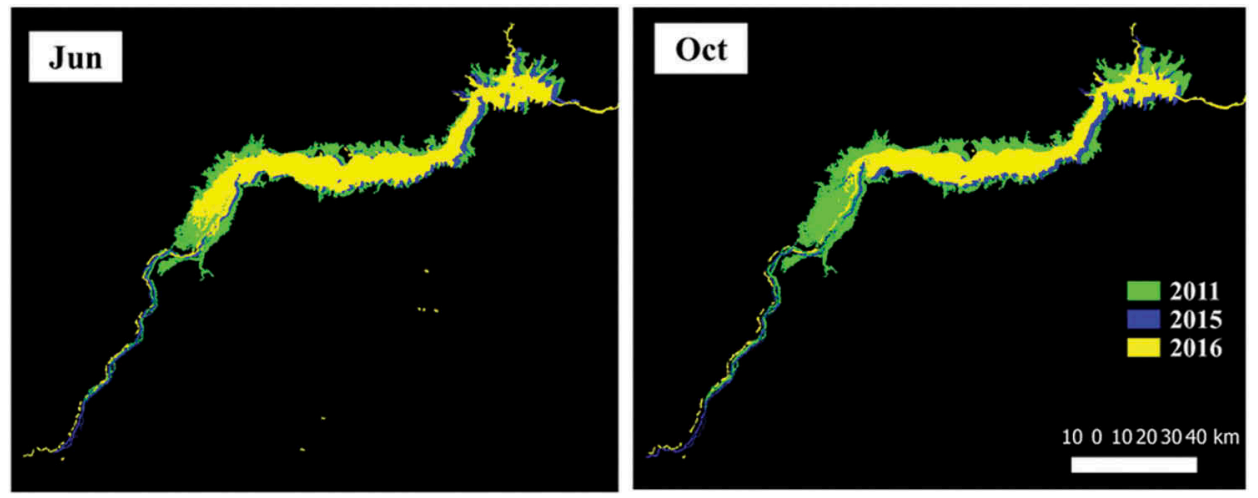

Figure 6. Temporal comparison of surface area of Sobradinho reservoir.

year June 2016 compared to the year June 2011. Table 1 shows the flooded water detected from NDWI by each date. This decrease was even higher during the dry spell with more than $50 \%$ in the month of Oct of 2015 and $46 \%$ in Oct 2016 compared to June 2011. The loss of surface water in the year 2015 was higher compared to 2016 due to the heavy rainfall in the first half of 2016. The month of June 2015 is considered as of maximum flood level after the rainy period, however, the surface area decreased to approximately $1250 \mathrm{~km}^{2}$ in June 2015 approximately half of total area detected in 2011 .

Temporal comparison of surface water (Figure 6) was carried out overlaying all yearly NWDI binary result for June and Oct. The decrease in surface area of the reservoir is clearly seen from 2015 (blue) and 2016 (yellow) compared with June 2011 (green). The yellow areas show hidden blue areas since 2016 have shown an increase in surface area due to strong rainfall compared to 2015. Visual comparison clearly shows depletion of the reservoir in the years 2015 and 2016 compared to 2011, likely from accumulated drought conditions observed since 2012. Although ANA has taken emergency action since 2015 after seeing the reduction in the water storage such as the reduction of minimum defluences of Sobradinho Reservoir, the depletion of water storage is evident.

\section{Conclusion}

The largest NEB reservoir, Sobradinho, shows severe water deficit due to continuous drought since 2012. Although drought is a recurrent phenomenon in this semi-arid region, this long-lasting event (2012-2016) was influenced by ENSO which has a direct impact on weather and ecosystems. The year of 2012 shows the least deviation in precipitation 
$\left(-265.55 \mathrm{~mm}\right.$ year $\left.^{-1}\right)$ with respect to the periods $2000-2016$. This reduction is followed by persistent higher temperatures and dry condition that strongly affected NDVI. Decrease upto 30\% in NDVI of May 2012 was observed compared with 17-years NDVI average. Additionally, the accumulative stress condition of vegetation is clearly observed from NDVI of 2015 compared to 2016, inspite of an increase in rainfall NDVI shows reduction.

The NDWI clearly shows changes and a strong reduction in surface water of Sobradinho reservoir. The surface water detected is coherent with values provided by the concessionaire of electric power responsible for the reservoir. Our temporal analysis indicates depletion of the reservoir with more than $50 \%$ and $46 \%$ of loss during 2015 and 2016 dry spell, respectively, with respect to June 2011. Although higher ET was observed in the year 2016 with more than $60 \%$ increase compared to an average of the whole period studied (2003-2016), due to strong rainfall change in surface water in the year 2016 was observed lower compared to the year 2015. Finally, it was emerged the importance of a comprehensive understanding of the linkage between the meteorological and hydrologic droughts. Such investigations can profit the subsidence to address extreme events as long-lasting drought that may impact Sobradinho reservoir and its power generation, which has already been reduced in November to an average generation of $170 \mathrm{MW}$, although has a total installed capacity of $1050 \mathrm{MW}$. Also, even with a set of politics to reduce the minimum outflow of the Sobradinho, a critical percent of active volume still occurring and the reservoir depletion.

\section{Acknowledgments}

The author (Samara Calçado de Azevedo) is thankful to FAPESP for the awarded fellowship (grant number 2015/26743-5) to visit Chapman University and for national project (grant number 2013/ 25257-4). The authors are grateful to the two anonymous Reviewers for their comments/suggestions to improve earlier version of the manuscript.

\section{Funding}

This work was supported by the Fundação de Amparo à Pesquisa do Estado de São Paulo [2013/ 25257-4, BEPE 2015/26743-5];

\section{ORCID}

Samara Calçado de Azevedo (iD) http://orcid.org/0000-0001-6237-3070

Guilherme Pina Cardim (D) http://orcid.org/0000-0003-3769-8433

Erivaldo Antonio da Silva (D) http://orcid.org/0000-0002-7069-0479

\section{References}

Agência Brasil. 2015. "Maior Reservatório Do Nordeste, Sobradinho Tem Seca Histórica." Accessed May 2017. http://agenciabrasil.ebc.com.br/geral/noticia/2015-11/maior-reservatorio-do-nor deste-sobradinho-tem-seca-historica.

ANA (Agência Nacional de Águas [Brasil]). 2016. Conjuntura Dos Recursos Hídricos: Informe 2016/ Agência Nacional De Águas. Brasília: ANA. 
Awange, J. L., F. Mpelasoka, and R. M. Goncalves. 2016. "When Every Drop Counts: Analysis of Droughts in Brazil for the 1901-2013 Period." Science of the Total Environment 566: 1472-1488. doi:10.1016/j.scitotenv.2016.06.031.

Barbosa, H. A., A. R. Huete, and W. E. Baethgen. 2006. "A 20-Year Study of NDVI Variability over the Northeast Region of Brazil." Journal of Arid Environments 67: 288-307. doi:10.1016/j. jaridenv.2006.02.022.

Barbosa, H. A., and T. V. Kumar. 2016. "Influence of Rainfall Variability on the Vegetation Dynamics over Northeastern Brazil." Journal of Arid Environments 124: 377-387. doi:10.1016/j. jaridenv.2015.08.015.

Beuchle, R., R. C. Grecchi, Y. E. Shimabukuro, R. Seliger, H. D. Eva, E. Sano, and F. Achard. 2015. "Land Cover Changes in the Brazilian Cerrado and Caatinga Biomes from 1990 to 2010 Based on a Systematic Remote Sensing Sampling Approach." Applied Geography 58: 116-127. doi:10.1016/j.apgeog.2015.01.017.

Cavalcanti, I. F. A. 2015. "The Influence of Extratropical Atlantic Ocean Region on Wet and Dry Years in North Northeastern Brazil." Frontiers in Environmental Science 3: 34. doi:10.3389/ fenvs.2015.00034.

Cunha, A. P. M., R. C. Alvalá, C. A. Nobre, and M. A. Carvalho. 2015. "Monitoring Vegetative Drought Dynamics in the Brazilian Semiarid Region." Agricultural and Forest Meteorology 214: 494-505. doi:10.1016/j.agrformet.2015.09.010.

Da Silva, V. D. P. R. 2004. "On Climate Variability in Northeast of Brazil." Journal of Arid Environments 58: 575-596. doi:10.1016/j.jaridenv.2003.12.002.

Kogan, F., and W. Guo. 2017. "Strong 2015-2016 El Niño and Implication to Global Ecosystems from Space Data." International Journal of Remote Sensing 38 (1): 161-178. doi:10.1080/ 01431161.2016 .1259679$.

Lucena, D. B., J. Servain, and M. F. Gomes Filho. 2011. "Rainfall Response in Northeast Brazil from Ocean Climate Variability during the Second Half of the Twentieth Century." Journal of Climate 24 (23): 6174-6184. doi:10.1175/2011JCLI4194.1.

Marengo, J. A., R. R. Torres, and L. M. Alves. 2016. “Drought in Northeast Brazil—Past, Present, and Future." Theoretical and Applied Climatology 1-12. doi:10.1007/s00704-016-1840-8.

McFeeters, S. K. 1996. "The Use of the Normalized Difference Water Index (NDWI) in the Delineation of Open Water Features." International Journal of Remote Sensing 17 (7): 14251432. doi:10.1080/01431169608948714.

Rodell, M., H. K. Beaudoing, T. S. L'Ecuyer, W. S. Olson, J. S. Famiglietti, P. R. Houser, R. Adler, et al. 2015. "The Observed State of the Water Cycle in the Early Twenty-First Century." Journal of Climate 28: 8289-8318. doi:10.1175/JCLI-D-14-00555.1.

Soille, P. 2003. Morphological Image Analysis. 2nd ed. Berlin, Germany: Springer-Verlag.

Sun, T., V. G. Ferreira, X. He, and S. A. Andam-Akorful. 2016. "Water Availability of São Francisco River Basin Based on a Space-Borne Geodetic Sensor." Water 8 (5): 213. doi:10.3390/w8050213. 